\title{
Effects of Additives on Some Selected Properties of Base Sand
}

\author{
Saliu Ojo Seidu ${ }^{*}$, Bolarinwa Johnson Kutelu² \\ ${ }^{1}$ Department of Metallurgical and Materials Engineering, Federal University of Technology, Akure, Nigeria \\ ${ }^{2}$ Department of Mineral Resources Engineering, Federal Polytechnic Ado-Ekiti, Nigeria \\ Email: seidu2@yahoo.co.uk
}

Received 11 April 2014; revised 7 June 2014; accepted 9 July 2014

Copyright (C) 2014 by authors and Scientific Research Publishing Inc.

This work is licensed under the Creative Commons Attribution International License (CC BY).

http://creativecommons.org/licenses/by/4.0/

(c) (i) Open Access

\section{Abstract}

In this study, effects of sawdust, coal dust and iron filling additives at varied proportions on some selected properties of moulding sand were investigated. Consequently, cylindrical specimens with different percentages of additives were prepared based on standard procedures. The prepared specimens were subjected to basic moulding sand testing including moisture content, bulk density, porosity, permeability, green compression strength and green shear strength using standard methods and equipment. From the obtained test results, all the experimental additives were found to improve the selected moulding properties of the base (silica) sand. Moulding sand specimen with sawdust additive revealed a relatively better compaction as compared to moulding sand specimens with coal dust and iron filling additives respectively. The moisture absorbing strength of the moulds was also found to increase with increasing percentage of sawdust. Addition of coal dust to the moulding sand was found to improve sand porosity and permeability which results in less casting defects, and due to improved moisture absorbing strength of sawdust, moulding sand specimens that contained sawdust were equally found to exhibit good compaction with maximum green compressive strength of $108.99 \mathrm{kPa}$. Also, the combination of $25 \%$ sawdust, coal dust and iron filling in the moulding sand was found to produce mould with optimum green shear strength value of $54.49 \mathrm{kPa}$.

\section{Keywords}

Moulding Sand, Sawdust, Coal Dust, Iron Filling, Porosity, Permeability, Bulk Density, Green Compressive Strength, Green Shear Strength

\footnotetext{
${ }^{*}$ Corresponding author.
}

How to cite this paper: Seidu, S.O. and Kutelu, B.J. (2014) Effects of Additives on Some Selected Properties of Base Sand. Journal of Minerals and Materials Characterization and Engineering, 2, 507-512. 


\section{Introduction}

The most common casting process used in the foundry industry is the sand cast system [1]. The principal constituents of moulding sands are: silica sand grains, clay (bond), moisture, and organic additives. Virtually all sand cast moulds for ferrous castings are of the green sand type [2]. Green sand consists of high-quality silica sand, about 10 percent bentonite clay, 2 to 5 percent water and about 5 percent sea coal; other materials may be added to the sand mixture to enhance certain properties [3], and for defects free cast products, foundry sand for mould making must be carefully prepared to meet certain basic requirements such as refractoriness, cohesiveness, permeability, collapsibility, green strength dry strength, thermal stability and reusability [1]. Moulding sands are specified based on average size and shape. Finer grains lead to more intimate contact and lower the permeability, but tend to fortify the mould and lessen its tendency to get distorted and the shapes of the grain may vary from round to angular [4].

A good moulding sand always represents a compromise between conflicting factors, and to obtain an acceptable compromise of the four basic requirements, the size of the sand particles, the amount of bonding agent (such as clay), the moisture content, and the percentage of organic matter are all selected [3]. The composition is carefully controlled to assure satisfactory and consistent results (A typical green-sand mixture contains about 85\% silica sand, 9\% clay, and 3\% water and 3\% organic additives). Moulding material is often reclaimed and recycled, the organic material that has to be added again as a portion of it will burn during the pour [5]. When moulding sands are used for mould making without additives, some important characteristic may be absent in the sand [6]. When additives are added to moulding sands, certain properties including high temperature plasticity, metal penetration property and surface finish are improved [2]. Additives are mixed during sand preparation based on the requirement of molten metal and base sand to obtain specific characteristics in the sand [3].

In spite of the property-enhancing influence of additives on castings from sand cast system, it is regrettable to note that while efforts by researchers on inoculation practice are on the increase, only scanty information on sand additives is available in literatures. Hence, qualities of cast products from the local foundries are found to come with some defects that are preventable when some specific properties are introduced into the base sand through additives.

This study, therefore examines the influence of sawdust, iron filling and coal dust (which are cheap and available) at varied proportions on the moisture content, permeability, porosity, bulk density, green compressive strength and green shear strength of the base sand that is silica sand with a view to determining the best mould(s) with correct additives proportion for sand cast system.

\section{Materials and Methods}

The materials used were silica sand, bentonite, coal dust, iron dust and sawdust. The equipment used included molding box, rammer and vent wire. The chemical composition of the silica sand used for this research is shown in Table 1.

\subsection{Sample Preparation}

Wooden patterns of $50 \mathrm{~mm}$ length, $30 \mathrm{~mm}$ breadth and $20 \mathrm{~mm}$ thickness with contraction allowance of 1.5\% were used to produce the test specimens. The sprue and riser were tapered to allow for easy withdrawal of pattern from the mould. Silica sand, bentonite (binder), water and additives ( iron filling, sawdust and coal dust) at different proportions were added to the mould materials, manually mixed and rammed together, blows were used for each of the ramming operation, and ramming was carried out with sand rammer in accordance with AFS specifications. Upon removing the specimens from the sand rammer, they were tested for moisture content, permeability, porosity, bulk density, compressive strength and shear strength. A specimen without additives (control) was equally prepared, and the results of the additive constituents of the produced moulding sand specimens used for the tests are depicted in Table 2.

Table 1. The chemical composition of the silica sand sample.

\begin{tabular}{cccccccc}
\hline Main Constituents & $\mathrm{SiO}_{2}$ & $\mathbf{A l}_{2} \mathbf{O}_{3}$ & $\mathbf{N a O}$ & $\mathbf{K}_{2} \mathbf{O}$ & $\mathbf{M g O}$ & $\mathbf{C a O}$ \\
\hline $\mathrm{Wt} \%$ & 97.21 & 0.36 & 0.73 & 0.12 & 0.36 & 0.47 \\
\hline
\end{tabular}


Table 2. Constituents of moulding sand specimens additive.

\begin{tabular}{ccc}
\hline Moulding Sand Specimens & Additives & Proportions of Mould Additives (\%) \\
\hline A & None & 0 \\
B & Iron dust & $20 \%$ \\
C & Iron dust & $25 \%$ \\
D & Sawdust & $20 \%$ \\
E & Sawdust & $25 \%$ \\
F & Charcoal dust & $25 \%$ \\
G & Iron dust and charcoal dust & $20 \%$ \\
H & Sawdust and charcoal dust & $25 \%$ \\
I & Sawdust, charcoal dust and iron dust & $20 \%$ \\
J & Sawdust, charcoal dust and iron dust & $25 \%$ \\
\hline
\end{tabular}

\subsection{Moulding Sand Testing}

Standard procedures and equipments were used to evaluate the moisture content, permeability, bulk density, green compressive strength, green shear strength and refractoriness of the moulding sand specimens.

\subsection{Moisture Content}

Specimens weighing 50 gm were carefully prepared and put inside an oven which was maintained at a temperature of $110^{\circ} \mathrm{C}$ for 2 hours to allow for the escape of moisture. After which, they were taken out of the oven and reweighed. The percentage of moisture was calculated from the difference in the weighs of the original moist and consequently dried sand samples using the expression:

$$
\text { Moisture Content }=\frac{w_{1}-w_{2}}{w_{1}}
$$

where,

$w_{1}=$ weight of the moist sand specimen

\subsection{Permeability}

$w_{2}=$ weight of the dried sand specimen

Air of volume $200 \mathrm{~cm}^{3}$ held in the bell jar was forced to pass through test specimens of dimensions $50.8 \mathrm{~mm}$ diameter and $50.8 \mathrm{~mm}$ long at a pressure of $980 \mathrm{~Pa}\left(10 \mathrm{~g} / \mathrm{cm}^{3}\right)$ indicated by the manometer reading, and the time required for the air to pass through the specimens was determined. The permeability number calculated using the formula:

$$
P_{A}=\frac{V \times H}{A \times P \times t} \quad(\text { Gupta, 2005) }
$$

where, $V=$ Volume of air $=200 \mathrm{~cm}^{3}$,

$$
\begin{aligned}
& H=\text { Height of the sand specimen }=50.8 \mathrm{~mm}=5.08 \mathrm{~cm}, \\
& P=\text { Air pressure }=10 \mathrm{~g} / \mathrm{cm}^{2}, \\
& A=\text { Cross sectional area of sand specimen }=\Pi / 4 \times(5.08)^{2}, \\
& t=\text { Time in minutes for complete air to pass through. }
\end{aligned}
$$

\subsection{Green Compressive Strength}

A portion of the rammed specimens were maintained in the green condition by taken them out of the moulding 
box, and without delay putting them immediately on the universal testing machine. Compressive loads were then applied until the specimens failed, and the force required to cause the compression failure were determined and recorded.

\subsection{Green Shear Strength}

The universal testing machine was fitted with a different adapter in order that loading can be made for the shearing of the rammed sand specimens. The stresses required to shear the specimens along the axis were determined and recorded as the green shear stress.

\subsection{Bulk Density}

Rammed specimens were weighed in air and the weights were recorded $(D)$. Thereafter, each of the specimens were transferred to a beaker of water and heated for 40 minutes to release any trapped air and they were allowed to cool. The specimens were soaked in water, and the soaked specimens were weighed and their weights were recorded $(W)$. The specimens were subsequently suspended in water and the suspended weights were measured (S). The bulk density was determined using the expression:

$$
\text { Bulk density }=\frac{D}{W-S}
$$

where: $D=$ Weight of specimen in air (dried sample),

$W=$ Weight of soaked specimen (in air),

$S=$ Weight of suspended specimen (in water).

\section{Results and Discussion}

Highest moisture content value of $39.2 \%$ was obtained for the specimens with $25 \%$ sawdust as compared to specimens with $25 \%$ iron filling and charcoal with moisture content values of $33.7 \%$ and $32.5 \%$ respectively. The observed improved moisture contents of all the specimens with varied percent of sawdust is an indication of the relative better moisture absorbing ability of sawdust [3], and as a consequence, mould sand compaction is increased due to reduction in the resistance developed by the bonding agent [1]. Hence, better mould strength requirement may be achieved in moulds with sawdust additive. Figure 1 shows the selected properties of moulding sand specimen relative to the varying quantity of additive addition.

Permeability, porosity and bulk density are critical to the strength requirement of sand moulds [7]. Generally, the specimens' permeability was observed to increase with increasing air filled porosity and decrease with bulk density [8]. Permeability is a function of the size of the sand particles, the amount and type of clay or bonding agent, the moisture content, and the compacting pressure [8]. In this study, variations in the moulding sand specimens' permeability, porosity and bulk density characteristics were observed to be direct consequence of the specimens' constituents. Relative improved permeability and porosity were obtained with charcoal dust containing moulding sand specimens as compared to iron filling and sawdust enriched specimens respectively. Specimen with $25 \%$ coal dust additive showed highest permeability and porosity values of $6.53 \times 10^{-5} \mathrm{~cm} / \mathrm{s}$ and $45.8 \%$ respectively, and the lowest values of $5.06 \times 10^{-5} \mathrm{~cm}$ permeability and porosity $33.2 \%$ was revealed by specimen with $25 \%$ sawdust. High moisture content in the mould has been found to decrease with increasing porosity and permeability [1]. Hence, relative less casting defects may be obtained with moulding sand that is rich in coal dust. The bulk density characteristics obtained for all the additive aided moulding sand specimens were seen to vary slightly, but comparable with that of the moulding sand specimen (control) without additive. The results obtained indicated that the specimens' bulk density characteristic was increased with increasing moisture content. At a very high moisture contents, maximum bulk density is achieved when the sand is adequately rammed to drive off all the air in the mould, and at low moisture contents, sand particles interfere with each other, such that addition of some moisture may be necessary for improved bulk density [1].

The relative improved green compressive and shear strength characteristics of the moulding sand specimens may have been influenced by the effects of the additives [9]. While the maximum green compressive strength value of $108.99 \mathrm{kPa}$ developed in the moulding sand specimen with $25 \%$ sawdust additive may be due to better mould compaction resulting from better moisture absorbing strength of sawdust [3], that of shear strength of value $54.49 \mathrm{kPa}$ revealed by specimen with $25 \%$ sawdust, coal dust and iron filling may be due to synergic effects of the additives which includes good moulding sand compaction, better moisture absorbing characteristics 

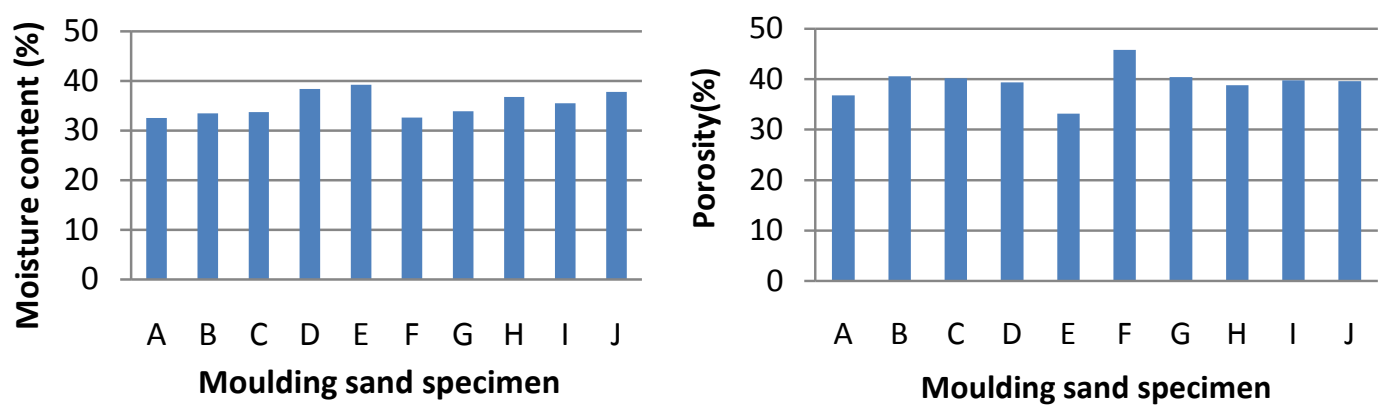

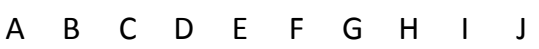

Moulding sand specimen
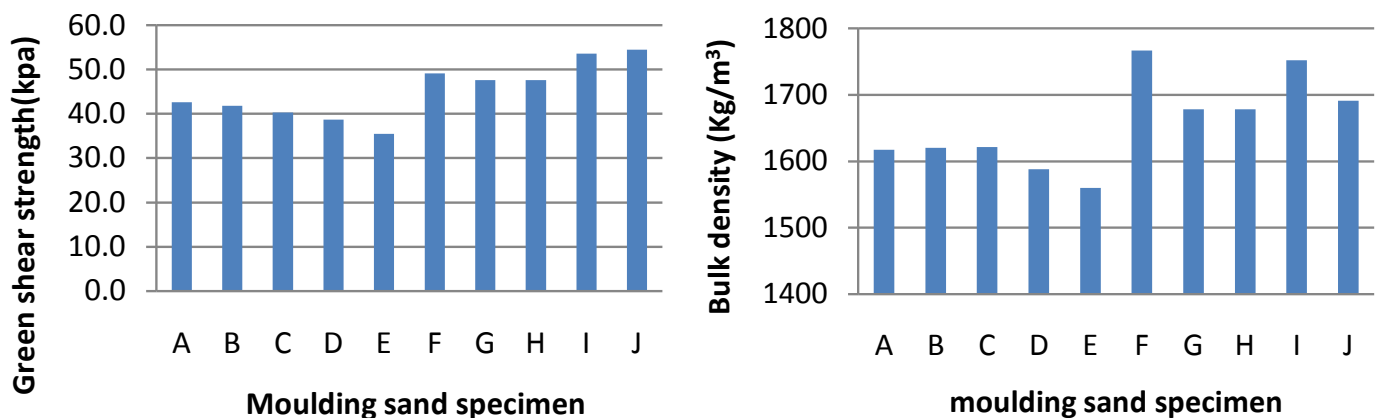

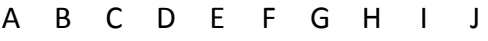

moulding sand specimen

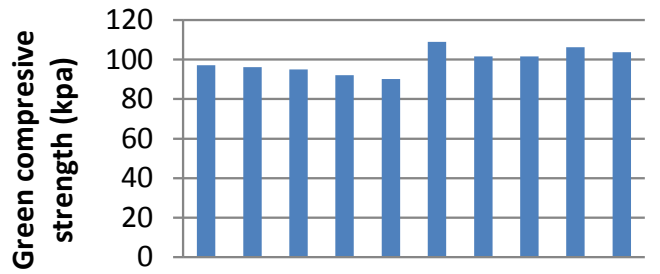

A

Moulding sand specimen

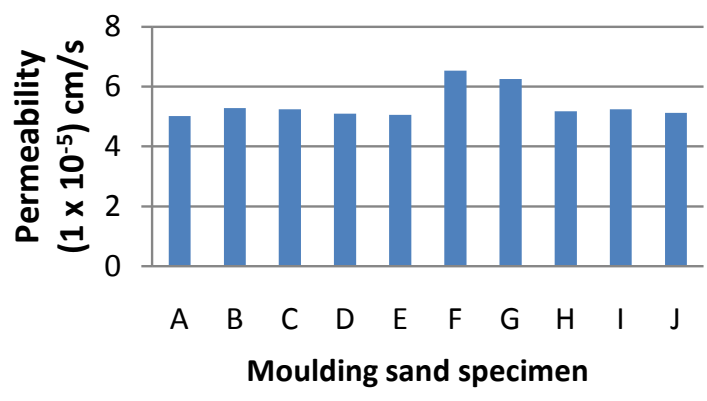

Figure 1. Selected properties of the moulding sand specimen.

of sawdust and resistance developed in the mould resulting from the relative poor moisture absorbing strengths of coal dust [3] and iron filling respectively. Consequently, sand moulds with optimum required moisture content, bulk density, porosity are produced.

\section{Conclusions}

Based on the obtained results of the moulding sand properties in this study, the following conclusions are made: 1. All the experimental additives were found to improve the moulding properties of the base (silica) sand.

2. Moulding sand specimens with sawdust additives revealed a relatively better compaction. Hence, improved mould strength requirement is achievable in moulds with sawdust additives.

3. The presence of coal dust in the moulding sand was found to improve sand porosity and permeability. Therefore, relative less casting defects including blow hole may be obtained with moulding sand that is rich in coal dust.

4. Due to improved moisture absorbing strength of sawdust, moulding sand specimens that contained sawdust were found to exhibit good compaction with maximum green compressive strength of $108.99 \mathrm{kPa}$.

5. The synergic effect of $25 \%$ sawdust, coal dust and iron filling on the moulding sand gave the optimum green shear strength value of $54.49 \mathrm{kPa}$. Hence, this combination should be preferred where what is optimally required is green shear strength.

\section{References}

[1] Adeleke, V.A. (2010) Effects of Addition of Iron (Fe) Filings to Green Moulding Sand on the Microstructure of Grey 
Cast Iron. Journal of the Brazilian Society of Mechanical Sciences and Engineering, XXXII, No. 2/175.

[2] Deepak, C. (2008) Green sand Management-Role \& Application of Carbonaceous Additives and Concept of Total Carbon in a Green Sand System. 68th World Foundry Congress, India, 127-132.

[3] Paul, A. (2011) Effects of the Moisture Content on the Foundry Properties of Yola Natural Sand. Leonardo Electronic Journal of Practices and Technologies, 19, 85-96.

[4] Aribo, S., Folorunso, D.O., Olaniran, O. and Oladele, I.O. (2009) Optimization the Green Compression Strength and Permeability of Green Sand Made from Epe Silica Sand. International Journal of science and Technology, 11, 101126.

[5] Beeley, P. (2001) The moulding Materials: Properties Preparation and Testing, Foundry Technology, ButterworthHeinemann, 2nd Edition, 178-443.

[6] Ameen, H.Z. and Hassan, K.S. (2011) Effect of the Sand Mould Additives on Some Mechanical Properties of Carbon Steel CK45 Casts. Journal of engineering, 17, 729-739.

[7] Aramide, F.A., Aribo, S. and Folorunso, D.O. (2011) Optimizing the Moulding Properties of Recycled Ilaro Silica Sand. Leonardo Journal of Sciences, 19, 93-102

[8] Mukherjees, P.C. (2003) Mould Section Material, Properties and Testing Fundamental of Metal Casting Technology. 703-754

[9] Seidu, S.O. (2013) The Effect of Carbonaceous Materials as Mould Additives on White Cast Iron. Annals of Faculty of Engineering Hunedoara. International Journal of Engineering, 11, 85-88. 
Scientific Research Publishing (SCIRP) is one of the largest Open Access journal publishers. It is currently publishing more than 200 open access, online, peer-reviewed journals covering a wide range of academic disciplines. SCIRP serves the worldwide academic communities and contributes to the progress and application of science with its publication.

Other selected journals from SCIRP are listed as below. Submit your manuscript to us via either submit@scirp.org or Online Submission Portal.
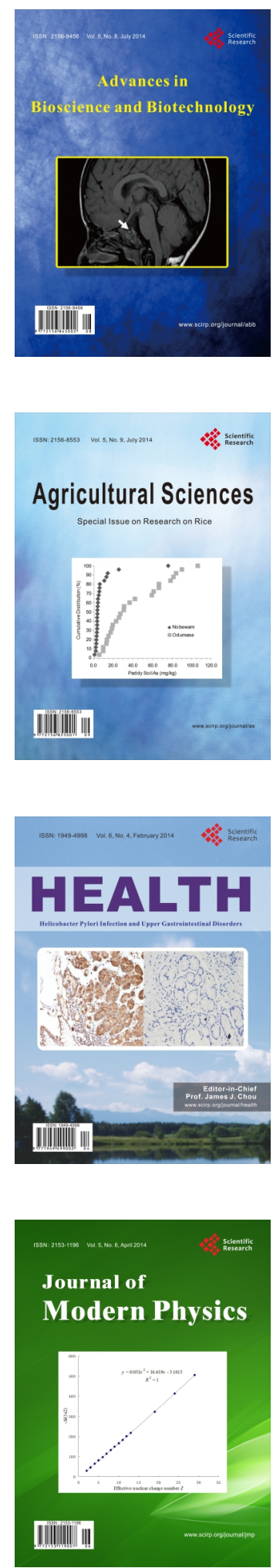
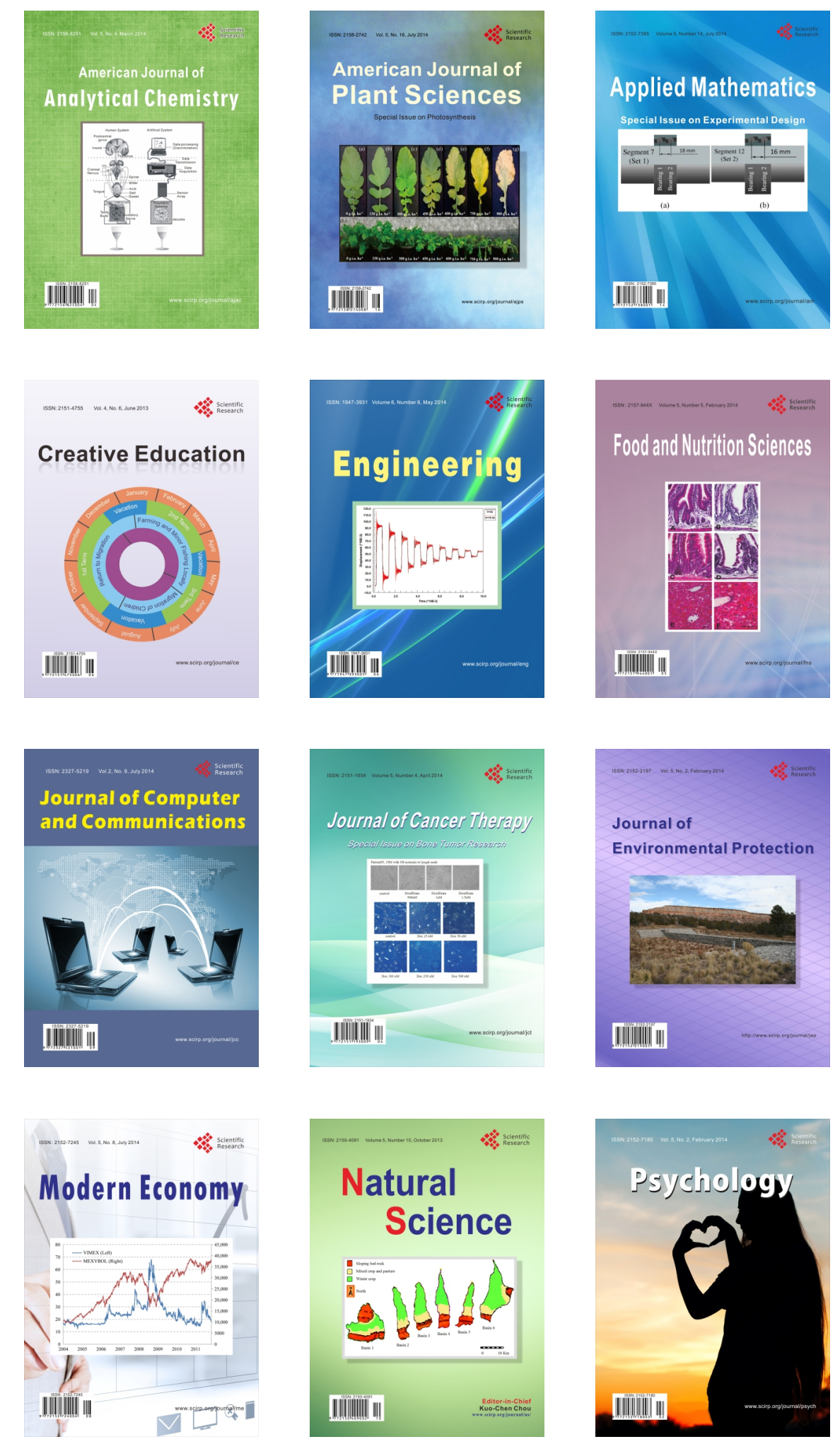